\title{
Três perspectivas de análise dos saberes: multidisciplinaridade e interdisciplinaridade
}

\author{
Fernanda Nunes da Rosa Mangini' \\ Lucídio Bianchetti \\ Universidade Federal de Santa Catarina
}

\section{Resumo}

As recentes discussões epistemológicas e teórico-metodológicas sobre o conceito de interdisciplinaridade e seus correlatos favorecem o levantamento da problemática de conceber e estabelecer relações democráticas e plurais entre os saberes comum e científico, tantas vezes apresentadas como antagônicas ou hierarquizadas. Objetiva-se, aqui, analisar tais conceitos, empregando como recurso metodológico a pesquisa bibliográfica. A partir da revisão de literatura, apresentam-se três vertentes de discussão das relações entre esses conhecimentos. Destacam-se como eixos norteadores deste trabalho: o sentido de superioridade atribuído à ciência; os conceitos congêneres de interdisciplinaridade; a valoração do saber comum e a relação entre ciência e política.

Palavras-chave: Conhecimento. Interdisciplinaridade. Ciência.

\section{Three perspectives of the analysis of knowledge: multidisciplinarity and interdisciplinarity}

\section{Abstract}

Recent epistemological and theoretical-methodological discussions about the concept of interdisciplinarity and related issues encourage a review of the problematic of conceiving and establishing democratic and plural relationships between common and scientific knowledge, which are often presented as having an antagonistic or hierarchical relationship. The objective of this study is to analyze these concepts, using bibliographic research as a methodological resource. Based on a review of the literature, three lines of discussion are presented that are related to these forms of knowledge. The guiding axis of this work include: the superiority attributed to science; concepts related to interdisciplinarity; respect for common knowledge and the relationship between science and politics. Keywords: Knowledge. Interdisciplinarity. Science. 
Três perspectivas de análise dos saberes: multidisciplinaridade e interdisciplinaridade

\section{Tres perspectivas para el análisis del conocimiento: la multidisciplina- riedad y la interdisciplinariedad}

\section{Resumo}

Los recientes debates epistemológicos y teórico-metodológicos sobre el concepto de interdisciplinariedad y sus correlatos plantearon la cuestión de examinar y establecer relaciones democráticas y plurales entre el conocimiento común y científico, muchas vezes presentadas como antagónicas o jerárquizadas. El objetivo es, aquí, el análisis de estos conceptos, empleando como recurso metodológico la investigación bibliográfica. Desde la revisión de la bibliografia, presentamos tres líneas de discusión de la relación entre estos conocimientos. Se destacan como ejes orientadores del presente trabajo: el sentido de superioridad de la ciencia; los conceptos congéneres de interdisciplinariedad; la valoración del conocimiento común y la relación entre la ciencia y la política.

Palavras-clave: Conocimiento. Interdisciplinaridad. Ciencia.

\section{Introdução}

A temática das relações entre os diferentes tipos de saberes pautou os debates acadêmicos e universitários dos últimos anos, fortemente inspirada pelos movimentos estudantis dos anos de 1968 e pelos desenvolvimentos teóricos em torno dos conceitos de interdisciplinaridade e de transdisciplinaridade. movimento pós-moderno também acabou transformando-se em um reforço à questão, ao contribuir com as denúncias à pretensão da ciência moderna ser apresentada como único e legítimo modo de conhecer. Além disto favoreceu a defesa de um modo democrático de conceber o conhecimento, sem a imposição de uma verdade absoluta, de um saber totalmente fundado e de uma visão de mundo como sistema racional completado.

Até então, os debates acadêmicos tendiam a realçar a oposição entre os conhecimentos científico e do senso comum. Nos últimos anos, a tendência aponta para o diálogo entre essas formas e conhecimentos em meio às suas particularidades e diferenças. No entanto, esse debate não é isento de problemas, a começar pela própria definição (e muitas vezes indefinição) dos conceitos de conhecimento científico, conhecimento comum, senso comum, bom senso, entre outros. Outro problema é situar a partir de qual perspectiva 
teórica abordam-se esses conceitos, uma vez que variam segundo o enfoque adotado.

No contexto brasileiro, as recentes ações afirmativas que favorecem o ingresso de alunos das camadas populares nos meios universitários suscitam o debate em torno dos saberes que trazem esses alunos e dos modos de relacioná-los com o conhecimento científico produzido e difundido nessas instituições. Desse modo, tanto no aspecto teórico quanto no aspecto prático e político da realidade, a questão dos tipos de conhecimentos e de suas relações adquire fundamental importância quando o que está em jogo é o desenvolvimento de ações democráticas e a garantia do compromisso com a qualidade do conhecimento produzido e veiculado.

Essa discussão assume a maior relevância para os educadores, tanto do ponto de vista de um exame crítico dos seus saberes quanto da forma como dialogam e estabelecem intercâmbios com os saberes dos indivíduos e grupos para os quais trabalham e os saberes destes.

Por meio do presente artigo, objetiva-se descrever e analisar esses conceitos a partir de uma revisão da bibliografia relacionada à temática, visando sistematizar as principais vertentes de discussão que abordam as relações entre os conhecimentos científico e do senso comum. Após a definição e a justificação da respectiva vertente, cada perspectiva será organizada de acordo com os seguintes eixos categoriais: sentido de superioridade atribuída à ciência, relação multi/interdisciplinaridade, valoração dos saberes não-científicos e relação entre ciência e política.

$\bigcirc$ artigo é estruturado em três vertentes, sendo a primeira, a perspectiva clássica, ilustrada por Mario Bunge (1919-), para o qual o conhecimento científico é superior ao vulgar e não necessita deste último. A segunda, a perspectiva marxista gramsciana, é representada pelo filósofo brasileiro Ari Paulo Jantsch (1958-2010) que, mesmo focando sua análise no conhecimento popular, compreende que o senso comum é sempre um obstáculo a ser superado. E a terceira, a perspectiva transformadora, é defendida por aqueles pensadores, como Boaventura Souza Santos (1940-) e outros, que se sentem compromissados com uma transformação social radical. Trata-se de autores que questionam a supremacia do saber científico sobre o senso comum, por entenderem que, de algum modo, o saber científico deve combinar-se com o saber não científico. 
Antes de adentrar na discussão de cada vertente propriamente dita, considera-se necessário fazer algumas distinções. As expressões conhecimento comum ou saber vulgar são utilizadas pelos autores de todas as vertentes, que também empregam outras expressões, como conhecimento ordinário, senso comum e conhecimento popular. Por estarem presentes, de algum modo, em todos eles, optou-se por utilizar essas expressões. No dicionário, o termo vulgar é sinônimo de vulgo, ou seja, popular. Significa ainda aquilo que é comum, ordinário, trivial ou usual. Essa palavra, às vezes, comporta um sentido pejorativo, significando algo reles, 'vulgar', desprezível, baixo; outras vezes, é apreendido no sentido mais positivo, designando aquilo que é sabido e notório, disseminado e muito conhecido.

De maneira geral, não há consenso, entre aqueles que se dedicam ao seu estudo, quanto a um modo único de denominação do conhecimento comum, o qual é tratado, por vezes, como sinônimo de senso comum e de conhecimento popular. Entre os autores brasileiros, Chauí (2008), por exemplo, trabalha com o conceito de senso comum, assim como Marconi e Lakatos (2010). No caso dos principais autores de cada vertente: Bunge (1980), usa muito a expressão conhecimento ordinário, vulgar ou comum; Jantsch (1995), 76 conhecimento popular e senso comum; já Santos (1989) trabalha mais com a noção de senso comum, embora também utilize a expressão saber vulgar.

Depreende-se que, às vezes, são confundidos os significados desses conceitos. Além desses, poderiam-se acrescentar outros, como o conceito de bom senso. Este último refere-se à capacidade de tomar boas decisões em circunstâncias problemáticas e difíceis, quando as regras e receitas do pensamento e das consideradas boas vivências parecem não funcionar. Aplica-se tanto ao conhecimento comum quanto ao conhecimento científico, possuindo um sentido positivo que indica racionalidade, ao contrário de "conhecimento vulgar" e de "senso comum" que, na literatura especializada, geralmente possuem um sentido negativo e irracional.

senso comum é frequentemente igualado ao conhecimento comum ou saber vulgar, mas pode ainda aludir ao que se considera sensato em uma determinada ordem de pensamentos. Já "conhecimento popular" é uma denominação que leva em conta o conhecimento comum, em vista de sua especificidade, por exemplo, o saber das rendeiras, dos analfabetos, dos militares. 
A partir dessas noções gerais, examinam-se tais conceitos em sua vertente correspondente. Destaca-se que a ordem de exposição segue uma ordem cronológica e didática, e não expressa preferência ou primazia de uma vertente sobre outra. Ao final, apontam-se possíveis limitações e contribuições de cada vertente apresentada.

\section{A perspectiva clássica}

Representada por Mario Bunge, um dos mais influentes defensores da distinção entre conhecimento vulgar e especializado. Por esta perspectiva clássica parte-se do reconhecimento da superioridade do saber científico sobre os conhecimentos vulgares e populares, visto que o conhecimento científico tem um caráter metódico e sistemático que as outras modalidades não possuem. É, pois, um saber especializado cuja superioridade decorre não necessariamente do seu conteúdo, mas sim do seu modo de conhecer, estruturado por um procedimento lógico de investigação e por um objetivo de aumentar e aprimorar constantemente o conhecimento. Na visão de Bunge (1980, p. 19), trata-se do modo "[...] más reciente, [...] más universal y [...] más provechoso de todos los estilos".

Bunge (1985) adverte que essa superioridade não significa perfeição, pois, se fosse assim, o saber científico já estaria extinto, uma vez que a sua própria lógica de justificação reside na existência de lacunas do saber, na possibilidade de indagar e aprimorar o conhecimento. Também adverte que o conhecimento vulgar pode estar mais à frente da ciência no que diz respeito ao conteúdo. Do seu ponto de vista, um fazendeiro pode estar mais apto a fazer previsões do tempo do que um meteorologista, um pedreiro pode corrigir os erros de um engenheiro e um poeta pode descrever os sentimentos e as emoções com mais profundidade do que um psicólogo. A diferença é que o modo de construir o conhecimento científico está pautado em critérios, como precisão, segurança e objetividade. Ainda que seja um conhecimento falível, está idealmente sempre disposto a corrigir-se a si mesmo.

conhecimento vulgar, pelo contrário, não se consubstancia com a objetividade (condução do saber de maneira impessoal), tampouco com a sistematização do saber em teorias, em enunciados testáveis e sujeitos à revisão, como se procede na atividade científica. Não obstante essas características 
do saber vulgar, Bunge (1985) parece ter uma visão bastante positiva dele, sobretudo quando vinculado ao bom senso, concebido pelo estudioso como um conhecimento que aspira à criticidade (adequação aos fatos) e à racionalidade (coerência).É possível aventar que, para a perspectiva clássica, é no bom senso que reside o ponto de equilíbrio entre o conhecimento vulgar, o senso comum e o conhecimento científico.

conhecimento vulgar está presente desde o princípio na atividade científica, por meio da linguagem comum, que é empregada como ponto de partida em todos os campos do saber. $O$ conhecimento vulgar também pode inspirar a construção de problemas científicos, ainda que em um nível bastante elementar, pois essa construção depende de um acúmulo de saber, e pode, igualmente, ser inspirada por outros conhecimentos científicos, novamente sujeitos à revisão e correção. Para Bunge:

[...] a medida que progresa, la investigación corrige o hasta rechaza porciones del acervo del conocimiento ordinario. Así se enriquece este último con los resultados de la ciencia: parte del sentido común de hoy día es resultado de la investigación científica de ayer: de hecho, la investigación científica empieza en el lugar mismo en que la experiencia y el conocimiento ordinarios dejan de resolver problemas o hasta de plantearlos. La ciencia no es una mera prolongación ni un simple afinamiento del conocimiento ordinario (BUNGE, 1980, p. 19-20).

Se a ciência fosse um mero prolongamento do conhecimento comum, ela se reduziria a uma dimensão empírica, espaço privilegiado do conhecimento comum que tem na vida cotidiana e na experiência privada seu ponto de partida para conhecer. Mas pelo contrário, a ciência encontra-se, muitas vezes, distante do conhecimento comum, pois trabalha com conceitos e objetos empiricamente não acessíveis ao leigo, como os conceitos de átomos, células etc. Mesmo naquelas ciências em que a experiência tem um papel fundamental, ela deve ser confrontada para ser verificada ou falseada, para que o conhecimento não se reduza à percepção e à ação imediatas que caracterizam o modo pelo qual o sujeito comum conhece ${ }^{2}$.

Nessa perspectiva de análise, não somente o conhecimento científico é mutável, mas também o conhecimento vulgar, que varia conforme a época (tempo) e o local (espaço) de sua produção e difusão. Por exemplo, um conhecimento científico pode tornar-se conhecimento comum (fragmento de alguma 
teoria refutada) e um conhecimento vulgar pode dar origem a um conhecimento científico. Baseando-nos, mais uma vez, em Bunge (1985), os conhecimentos básicos de aritmética, física e tecnologia têm se tornado conhecimento vulgar em países industrializados, embora ainda sejam conhecimentos especializados em nações subdesenvolvidas.

Isso leva a crer que no pensamento de Mario Bunge os conhecimentos científico e vulgar estão em constante relacionamento (diálogo), embora de um modo mais propriamente multidisciplinar do que interdisciplinar, pois as formas de construir e validar cada conhecimento são distintas (desde a formulação de enunciados até o exame de suas afirmações) ${ }^{3}$. Ainda que ocorra alguma troca no nível dos conteúdos, cada saber vai proceder de forma distinta antes de qualquer integração, a ciência procedendo a exame crítico e revisão.

Como exposto anteriormente, o conhecimento científico pode alterar o conhecimento vulgar. De igual forma, o conhecimento vulgar pode interferir no desenvolvimento da atividade científica, tanto de um modo positivo (suscitando a formulação de problemas e até mesmo como modo de pensar contrário e divergente) quanto de um modo negativo (pequenas porções de verdades cristalizadas ou dogmas que podem limitar o fazer científico). Um exemplo dado por Bunge (1985) a respeito dessa distorção é a tenacidade com que alguns físicos se agarram à interpretação positivista da mecânica quântica, e até mesmo, por vezes, tentam suprimir o dissenso.

Pode-se observar o sentido negativo e positivo atribuído por Mario Bunge ao conhecimento vulgar quando o autor classifica esse conhecimento em: técnico, protociência e pseudociência.

conhecimento técnico é aquele que caracteriza as artes e as habilidades profissionais, algumas vezes empregadas pelos cientistas e enriquecidas com a ciência, embora de caráter não científico.

A protociência ou ciência embrionária, como o próprio nome sugere, é aquela atividade que condensa um trabalho cuidadoso, mas ainda sem o objetivo teórico que caracteriza a ciência. Pode suprir a ciência de dados brutos, embora contenha informações também irrelevantes.

A pseudociência é aquele corpo de crenças e práticas que ingenuamente ou de má fé é apresentada como ciência, embora não compartilhe nenhum aspecto em comum com a ciência (hipóteses, técnicas, corpo de conhecimentos etc.). A pseudociência, para Bunge, da qual a psicanálise e o 
Três perspectivas de análise dos saberes: multidisciplinaridade e interdisciplinaridade

espiritismo seriam exemplos, ocupa um espaço considerável na cultura urbana popular.

No pensamento do autor supracitado, a técnica e a protociência possuem um sentido mais positivo, ao passo que a pseudociência tem um sentido mais negativo, por ser apresentada erroneamente como ciência e por não buscar tornar-se científica ${ }^{4}$. Na visão de Bunge (1980), o problema da pseudociência é que os seus protagonistas geralmente se negam a adotar os procedimentos científicos (fundamentar suas doutrinas, colocá-las sob teste e experimentação etc.) e se recusam a corrigir-se a si mesmos, desprezando os novos descobrimentos científicos, reinterpretando seus fracassos como se fossem confirmações e tomando as críticas como um ataque. Nas palavras do autor, "[...] si ni la argumentación ni la experiencia pueden resquebrajar una doctrina, entonces esa doctrina es un dogma, no una ciencia" (BUNGE, 1980, p. 60).

A ciência é, para o autor, uma atividade na qual sobressai o conhecimento como valor central. Secundariamente, ela pode ser utilizada para promover o bem-estar das populações, apesar de não ser esse seu objetivo principal ou intrínseco. Os principais benefícios da ciência ou de uma ampla 80 difusão da atitude científica consistem em que, por meio dela são produzidas transformações de mentalidade e de comportamento nos indivíduos e grupos. São palavras do autor:

La adopción universal de una actitud científica puede hacernos más sabios: nos haría más cautos, sin duda, en la recepción de la información, en la admisión de creencias y en la formulación de previsiones; nos haría más exigentes en la contrastación de nuestras opiniones, y más tolerantes con las de otros; nos haría más dispuestos a inquirir libremente acerca de nuevas posibilidades, y a eliminar mitos consagrados que sólo son mitos, robustecería nuestra confianza en la experiencia, guiada por la razón y nuestra confianza en la razón contrastada por la experiencia; nos estimularía a planear y controlar mejor la acción, a seleccionar nuestros fines y a buscar normas de conducta coherentes con esos fines y con el conocimiento disponible, en vez de dominadas por el hábito y por la autoridad; daría más vida al amor de la verdad, a la disposición de reconocer el proprio error, a buscar la perfección y a comprender la imperfección inevitable; nos daría una visión del mundo eternamente joven, basada en teorías contrastadas, en vez de estarlo en la tradición, que rehúye tenazmente todo contraste 
con los hechos; y nos animaría a sostener una visión realista de la vida humana, una visión equilibrada, ni optimista ni pesimista (BUNGE, 1980, p. 51).

Embora essas mudanças se processem em escala limitada, para Bunge (1980), já é possível observar os frutos da difusão de uma atitude científica no âmbito da cultura.

A perspectiva apresentada na sequência continua enfatizando a distinção entre os conhecimentos científicos e vulgares, sendo até mais radical no tocante a essa separação.

\section{A perspectiva marxista gramsciana}

É a perspectiva cujos intérpretes inspiraram-se nas obras de Karl Marx (1818-1883) e especialmente de Antônio Gramsci (1891-1937)5 para pensar a relação entre conhecimento científico e o popular sob um ponto de vista político e epistemológico. Por meio desta perspectiva, visa-se a transformação social, mas à diferença da perspectiva transformadora, que será apresentada na sequência, seus proponentes entendem que é preciso garantir o acesso dos setores populares aos produtos mais elevados do conhecimento, que são a ciência e a tecnologia.

Um de seus intérpretes, o filósofo brasileiro Ari Paulo Jantsch, abordou o conhecimento vulgar e o senso comum sob o aspecto mais específico do conhecimento popular ${ }^{b}$. Apesar de reconhecer a necessidade de diálogo entre o senso comum e o conhecimento científico, defendeu a superação desse saber comum e até mesmo do bom senso pelo conhecimento científico 7 . No entendimento de Jantsch (1995), o bom senso é nada mais do que um refinamento do senso comum. Somente o conhecimento científico permite o desenvolvimento de uma práxis crítica, criativa, revolucionária e transformadora.

Nesta vertente, assim como na perspectiva clássica anteriormente apresentada, a superioridade do conhecimento científico decorre do modo ou do processo pelo qual o saber é construído, e não dos objetos de conhecimento. Mesmo porque, pelo conhecimento científico não se tem em vista a formação de uma verdade final ou de um conhecimento pronto e acabado. Este é superior justamente porque está pautado na construção de verdades provisórias, passíveis de confirmação, aprimoramento e revisão. 
cultivo da atitude científica permite alcançar diversos objetivos: a crítica, entendida como o olhar da realidade a partir de critérios objetivos, por meio de dados, de metas ou de avaliações; a criação, compreendida como a superação de um estado de coisas, de um mundo dado, cristalizado e dogmatizado; a revolução, ou seja, a construção de mudanças radicais que rompam com um mundo compreendido de maneira superficial e enganosa; e a transformação, o alcance de novos mundos. Este último objetivo seria a materialização ou concretização dos elementos crítico, criativo e revolucionário (JANTSCH, 1995).

$\bigcirc$ conhecimento popular torna-se relevante como questão epistemológica devido às suas possíveis interações com o conhecimento científico, a começar pela linguagem cotidiana. É por meio desta que se processam as primeiras ligações com o conhecimento científico. Aqui, a linguagem cotidiana, por sua vez, é aquela próxima da experiência e de outros conhecimentos pré-teóricos que estão presentes no fazer e no agir rotineiro do ser humano, nas relações com ele mesmo e com os outros. Um exemplo dessa linguagem cotidiana é o ato de dirigir um automóvel ou de usar um martelo (PAVIANI, 2009).

No entanto, nesta perspectiva, não é possível demarcar fronteiras rígi82 das entre os saberes científico e popular, tendo em vista que nenhum deles está livre das interações com o outro, não havendo um conhecimento científico ou popular puro. Isso não significa, entretanto, defender uma relativa interdisciplinaridade entre eles. Pelo contrário, parece mais adequado falar em uma multidisciplinaridade entre esses saberes, levando em conta as suas diferenças e evitando cair em homogeneizações simplificadoras. Mesmo porque no diálogo com o conhecimento popular o importante é alcançar o "motor epistemológico" (UANTSCH; BIANCHETTI, 201 1, p. 174), isto é, o avanço do conhecimento, que, por sua vez, se traduz no desenvolvimento da alta ciência e tecnologia.

conhecimento popular é, todavia, um conhecimento que se almeja superar, pois indica um modo subalterno de se relacionar e de se apropriar do complexo chamado conhecimento. Os autores que se enquadram nesta perspectiva consideram como conhecimento do povo "todo aquele que não é científico". É geralmente um saber atribuído às pessoas das camadas populares, cujas condições socioeconômicas são limitadas, mas, na verdade, não se restringe a elas. $\bigcirc$ conhecimento comum 
[...] não é um privilégio dos indivíduos populares, mas está presente, também, nas elites políticas e econômicas [...]. Por outro lado, é a condição que coloca as elites em condições favoráveis na relação com a ciência, a filosofia e a tecnologia UANTSCH, 1995, p. 162).

Em seus estudos, Schaefer e Jantsch (1995) atribuem um sentido mais negativo do que positivo às características do conhecimento popular, mesmo considerando-o como um saber que muda conforme a sociedade e a época de sua elaboração e transmissão. Os autores entendem ser um conhecimento que não consegue administrar de maneira lógica as peças ultrapassadas, conservadoras e reacionárias do seu saber (aspecto negativo) com os seus elementos criadores, inovadores e progressistas (aspecto positivo), mantendo-os sem solução. Para os autores, o conhecimento popular caracteriza-se pela ambiguidade, heterogeneidade, fragmentariedade, acriticidade, imediaticidade e dogmaticidade.

A ambiguidade é expressa pela falta de clareza nas situações reais, não implicando, necessariamente, contradição. O pensamento ambíguo é percorrido por um polo positivo (lugar do "sim", da afirmação) e por outro polo negativo (espaço do "não", da negação), sem haver qualquer decisão cognitiva por algum dos dois, de maneira que ambos convivem sem solução. Cita-se aqui o exemplo dado pelos próprios autores ${ }^{8}$, de um sujeito que manifesta posições ambíguas em dois momentos quando questionado sobre o governo:

Sim, através das eleições vamos tirar Sarney da presidência e seu substituto vai melhorar a situação do país. Não: no futuro, ou seja, com o novo governante eleito vai ser a mesma coisa, não adianta. Esse 'não' se refere não somente ao governante a ser eleito, mas a si mesmo como não-sujeito de mudanças, pois as mudanças, quando vêm, se originam politicamente fora e longe do indivíduo que as espera e deseja (SCHAEFER; JANTSCH, 1995, p. 34).

A heterogeneidade refere-se à falta de coerência ou ao agregado inconsistente de ideias e representações que impedem o desenvolvimento de níveis maiores de abstração cognitiva. Trata-se do ajuntamento indiscriminado e acrítico dos resquícios de cultura e de saberes atuais e passados, sejam estes de origem científica ou não, os quais conformam, de acordo com 
o entendimento de Schaefer e Jantsch (1995, p. 49), uma espécie "colcha de retalhos" cognitiva.

A tendência de aplicação do conhecimento popular é de voltar-se mais àqueles assuntos ou temas que têm mais afinidade com o universo pessoal das camadas populares, como aspectos do seu cotidiano e do seu trabalho, restringindo-se à experiência sensível. No geral, os componentes das classes populares não conseguem identificar o fio condutor de um pensamento ou as causas de uma determinada situação. É quando ocorre o "emparelhamento" ou a "intraposição" conceitual, para usar os termos dos autores, que significa a sobreposição acrítica de um conceito sobre outro, ocasionando a junção e a indistinção de ambos, como se fossem a mesma coisa. Segundo os autores, mesclar o poder de Deus com o poder humano seria um exemplo de "intraposição" do conceito religioso no profano.

A fragmentariedade é a falta de articulação dos conteúdos do saber em um todo lógico. $\bigcirc$ pensamento permanece diluído e cindido, é por isso que o indivíduo revela dificuldades de fazer sínteses abrangentes, tendo uma compreensão reduzida de espaço e de tempo. Um exemplo é a dificuldade dos componentes das classes populares de relacionar os conceitos do jurídico, 84 do político, do econômico, do cultural etc.

A acriticidade é a presença constante de todos os elementos anteriores ou a dificuldade de eliminar a prática cognitiva ambígua, heterogênea e fragmentária. A acriticidade também se expressa na ausência de dados objetivos. Um exemplo de acriticidade é a tendência a não ver a questão do poder como produto humano, tornando-o algo extra-humano, mágico ou sobrenatural.

A imediaticidade é a falta de distanciamento dos fatos, que está relacionada a dificuldades de abstração e à fixação em representações mentais sensíveis. Exemplos de imediatismo podem ser observados nos conceitos populares de "democracia", significando apenas as eleições diretas para presidente, ou de economia, representando estritamente uma melhora na vida pessoal, nos salários, no bairro etc? .

A dogmaticidade materializa-se na opção por um estado de segurança cognitiva no qual se tem dificuldade para discutir as próprias certezas. Exemplos: a certeza de outra vida, (no céu e no inferno), da imortalidade da alma, da existência de santos e de santas (como seres com poderes espirituais diversos) etc. Conforme os autores, é necessário superar o conhecimento popular, pois 
[...] o dogmatismo deixaria o indivíduo numa espécie de inércia mental (resistência a modificar o movimento cognitivo, sua dinâmica, seu processo e seus resultados conceituais). A capacidade de crítica que poderia imprimir novo movimento - pelo exercício da dúvida, por exemplo - apesar de existir na lógica-processual popular, não conseguiria ser suficiente para quebrar a inércia. Enquanto permanecesse esse estado de coisas o conhecimento popular continuaria dogmático. $\bigcirc$ importante para o nosso caso é atentar para a impressão real de segurança intelectual que o pensamento dogmático oferece ao homem do senso comum (SCHAEFER; JANTSCH, 1995, p. 26).

Além disso, a dogmaticidade consiste em um modo de pensar rígido e conformista, que pode contribuir para o desenvolvimento de atitudes de submissão políitico-econômica. Um exemplo é a interpretação popular dos problemas desse âmbito como expressão das provas e expiações de culpas neste mundo terreno que, por sua vez, supõem o sofrimento e a resignação. O pensamento dogmático é aquele em que se atribui maior peso à segurança de supostas verdades do que aos processos cognitivos de duvidar ou questionar as suas próprias crenças, noções, ideias, seus conceitos, valores, suas concepções de mundo etc.

Quanto à relação entre ciência e política, o problema não parece ser a atividade científica em si, mas a sua apropriação pelas classes sociais. $\mathrm{Na}$ opinião dos autores desta vertente, é possível desenvolver uma ciência e um conhecimento científico livre dos direcionamentos políiticos (esquerda ou direita, socialismo ou capitalismo, dominação ou libertação). A tarefa principal residiria em promover a construção de contra-hegemonias aos modos particularistas e privatistas de apropriação e usufruto do conhecimento científico-tecnológico. Isto porque o reconhecimento é objeto de disputa entre classes sociais (entre elas e dentro delas), de modo que se faz necessário refletir sobre a relação que cada classe tem com o conhecimento desde sua elaboração até seu uso final.

O conhecimento popular está presente em todas as classes, embora de modo predominante naquelas que têm menos acesso ao conhecimento científico $^{10}$. Por isso, o importante é superar a desigualdade de acesso, construção e socialização do saber científico, a fim de não desenvolver uma atitude hostil em face dos conhecimentos populares, mas sim de aproveitá-los como elemento de dúvida e de criação ${ }^{1}$. Evidenciando a preocupação com a qualidade do conhecimento científico e com as transformações sociais, a inclusão social tem 
Três perspectivas de análise dos saberes: multidisciplinaridade e interdisciplinaridade

mais condições de acontecer à medida que os sujeitos cognitivos possuam mais chances para se apropriar do conhecimento científico ou produzi-lo.

Na opinião de Jantsch (1995, p. 136), " [...] insistir no senso comum [isto é, conformar-se com ele] não é favor algum, nem a indivíduos, nem a camada popular (classe) - pelo contrário, é condená-los de vez à situação de inferioridade no jogo das relações econômicas e sociais." Na luta política contra a apropriação particularizada da ciência e em busca da democratização do saber, bem como da universalização da ciência e da habilidade de fazê-la, é fundamental invocar a historicidade a partir da qual se busca

[...] o real dos grupos populares em seu movimento e/ ou dinâmica, seja no seu reino de senso comum, seja na busca da concepção científica e na participação do processo coletivo de construção do conhecimento. Sem esta postura fica difícil projetar superações das condições limitativas dos grupos e pessoas populares UANTSCH 1995, p. 146).

É sobre esta aparente supervalorização do conhecimento científico que autores como Boaventura de Souza Santos marcaram sua divergência, 86 como será exposto a seguir.

\section{A perspectiva transformadora}

Por meio dessa perspectiva, entende-se o conhecimento como elemento fundamental para a transformação social, sendo esta fortemente influenciada pelo movimento pós-moderno. François Lyotard (1924-1998), em seu livro "A condição pós-moderna", abordou a questão do conhecimento nas sociedades pós-industriais, situando a ciência como um subconjunto de conhecimento e o saber como atributo não exclusivo da ciência. Conforme o autor, trata-se de um pensamento atento aos erros da ciência e preocupado com o respeito e a igualdade entre os saberes de outros povos (LYOTARD, 2004).

A ciência é compreendida por Lyotard como o modo de pensar hegemônico da Modernidade, que contribuiu para instaurar a violência e a desigualdade entre os saberes. Nessa perspectiva, o ideal de emancipação realizaria-se por meio da dissolução dos absolutos, neste caso, da ciência como única verdade válida. $\bigcirc$ pensamento pós-moderno é, essencialmente, 
um pensamento por meio do qual se defende um conhecimento livre de hierarquias e condenam-se as guerras que foram feitas em nome da verdade. Talvez, por isso, entenda-se que se devam formar acordos provisórios capazes de romper com o totalitarismo de uma única noção de verdade, de uma lei universal, uma vez que a verdade é força, é poder (VATTIMO; ROVATTI, 1988; VATTIMO, 2007).

Parece ser nessa mesma linha que o sociólogo português Boaventura de Souza Santos defende que não há superioridade do conhecimento científico. Em sua visão, trata-se de um saber que aniquila os conhecimentos alternativos dos povos e dos grupos sociais cujas práticas neles fundamentam-se. Isto porque a ciência procede de modo polarizado ou rivalizado com essas formas de conhecimento, isto é, primeiro os recusa para depois transformá-los em matéria-prima com vistas ao desenvolvimento de seu próprio campo.

As classificações hierárquicas que se estabelecem a partir do conhecimento científico para distingui-lo de outros saberes carecem de fundamento e sentido, tanto do ponto de vista dos métodos da ciência como do conhecimento produzido por ela. Tal distinção está pautada em um juízo de valor e, no caso da ciência, é esse juízo que determina a sua preferência entre outras práticas cognitivas. São esses mesmos valores, que foram negados pela ciência clássica, por serem considerados aspectos meramente "subjetivos" e indesejáveis, que, na verdade, definem a primazia da ciência moderna e atribuem sentido ao conhecimento desta.

Na busca por rigor e precisão, os 'profetas' da ciência moderna, portanto, acabam por reduzir a complexidade do mundo e desqualificá-lo. Os prejuízos ao conteúdo desse saber decorrem da fixação à forma, que tem no modelo da matemática o exemplo de redução da qualidade à quantidade. Com isso, constrói-se um conhecimento que tem como resultado um estreitamento em relação a outros saberes e, mesmo que tenha contribuído para a sobrevivência humana, não reverteu em sabedoria para a vida. Essa seria a principal falha da ciência moderna, na visão de Santos, já que o saber da ciência não contribui para a transformação.

A ciência clássica, construída por Isaac Newton (1642-1727), Francis Bacon (1561-1626), René Descartes (1596-1650), entre outros, procede de modo totalitário, negando o caráter de racionalidade a todas as outras formas de saber que não adotem seus princípios epistemológicos e suas regras 
Três perspectivas de análise dos saberes: multidisciplinaridade e interdisciplinaridade

metodológicas. A introdução de novos desenvolvimentos teóricos, como os de Albert Einstein (1879-1955), os da física quântica e os questionamentos a respeito do rigor da matemática são, para Santos (2009), elementos que colocam em questão a superioridade da ciência e a sua racionalidade.

procedimento analítico, característico da ciência clássica, é responsável, conforme o autor citado, por reduzir o real, porque divide e classifica, para depois tentar juntar o que fragmentou. Na mesma direção, o saber disciplinar da ciência clássica tornou o cientista, na visão de Santos (2009, p. 74), um "ignorante especializado". As disciplinas delimitam fronteiras rígidas e impõem limites à transposição destas, segregando os saberes entre si. Em face dessa situação, a aposta de Santos (2009) reside na diluição das fronteiras disciplinares e na flexibilização das divisões rígidas entre a ciência, o saber vulgar e as humanidades, como afirma na citação a seguir:

Na concepção que aqui defendo, é o da superação da distinção entre ciência e senso comum e da transformação de ambos numa nova forma de conhecimento, simultaneamente mais reflexivo e mais prático, mais democrático e mais emancipador do que qualquer um deles em separado (SANTOS, 1989, p. 86).

Em outras palavras, a proposta de Santos contém elementos na direção de uma inter/transdisciplinaridade entre os conhecimentos, a partir do momento que vislumbra não somente o diálogo, mas também os pontos de confluência entre os saberes, com base em suas interações (produção do conhecimento de forma "horizontal" e "compartilhada"). Trata-se de articular uma pluralidade metodológica pautada na imaginação e em critérios pessoais do cientista, com o intuito de converter os saberes em sabedoria de vida, que pode traduzir-se em desenvolvimento do conhecimento, inovação, aprendizado e transformação social.

Por meio do senso comum orienta-se e dá-se sentido às práticas humanas. É o conhecimento da vida, que possui uma direção articulada a um propósito, ao contrário da ciência clássica, que se restringe a averiguar como funciona determinado setor da realidade, em termos gerais. Em vista disso, parece que se atribui um sentido mais positivo do que negativo ao conhecimento comum, por este ser um saber pautado na experiência, que, para essa perspectiva, não se deve desperdiçar (nem isolar e tampouco desprezar). A experiência e o hábito de decidir bem formam as bases da sabedoria prática, 
ou melhor, da sabedoria para a vida. É por isso que Santos (2009) se inspira na sabedoria oriental e na sabedoria de povos indígenas e camponeses.

A sabedoria oriental, ao não estabelecer dicotomias no seu modo de conhecer, é considerada muito mais global e holística, porque não separa as partes de suas totalidades cósmicas la exemplo da multiplicidade de tempos, circulares e lineares, e da ideia de reencarnação). Já a sabedoria de povos indígenas e camponeses é vista como a melhor alternativa para preservar a biodiversidade, que se encontra mais conservada justamente nas áreas onde habitam esses povos. Segundo Santos (2007, p. 33), " [... é porque a natureza neles é a Pachamama [...]", que significa a mãe terra dos incas.

Daí a necessidade de afirmar e reconhecer os diferentes tipos de saberes, condição necessária para uma "ecologia dos saberes". Em termos práticos, isso significa o reconhecimento dos méritos da ciência e de outras formas de saber. Para ser fiel ao pensamento do autor, significa reconhecer, por exemplo, que a ciência é o melhor conhecimento para levar o homem ou a mulher à Lua, embora não o seja para preservar a biodiversidade. Nesse caso, "[...] de nada serve a ciência moderna. Ao contrário ela a destrói. Porque o que vem conservando e mantendo a biodiversidade são os conhecimentos indígenas e camponeses" (SANTOS, 2007, p. 33).

A proposta da "ecologia dos saberes" pressupõe que não há justiça global sem uma justiça entre os conhecimentos:

[...] Não se trata de 'descredibilizar' as ciências nem de um fundamentalismo essencialista 'anticiência'[...]. O que vamos tentar fazer é o uso contra-hegemônico da ciência hegemônica. Ou seja, a possibilidade de que a ciência entre não como monocultura mas como parte de uma ecologia mais ampla de saberes, em que o saber científico possa dialogar com o saber laico, com o saber popular, com o saber dos indígenas, com o saber das populações urbanas marginais, com o saber camponês. [...] (SANTOS, 2007, p. 33).

Nesse sentido é que o autor aposta em uma nova relação entre a ciência, o senso comum e o conhecimento popular, longe daquela visão da ciência clássica, que concebe o saber não científico a partir de um ponto de vista etnocêntrico e o percebe negativamente, como algo: ilusório, superficial, falso; conservador, enviesado etc. Esse caráter ilusório, conservador ou 
Três perspectivas de análise dos saberes: multidisciplinaridade e interdisciplinaridade

preconceituoso do senso comum pode ser mais ou menos acentuado, dependendo das relações sociais em que esse conceito é construído e refletido ${ }^{12}$. "Senso comum" não é um conceito fixo e estático. Na concepção do autor, uma sociedade democrática com desigualdades pouco acentuadas, que tenha um sistema educativo generalizado e orientado por uma pedagogia libertária, provavelmente produzirá um senso comum diferente daquele produzido por uma sociedade autoritária, com forte desigualdade e ignorância (SANTOS, 1989).

Considerando não somente os elementos negativos do senso comum, mas também os seus aspectos positivos, na perspectiva do autor, conclui-se que:

[...] o senso comum faz coincidir causa e intenção; subjaz-the uma visão do mundo assente na ação e no princípio da criatividade e das responsabilidades individuais. $\bigcirc$ senso comum é prático e pragmático; reproduz-se colado às trajetórias e às experiências de vida de um dado grupo social e nessa correspondência se afirma de confiança e dá segurança. $\bigcirc$ senso comum é transparente e evidente; desconfia da opacidade dos objetos tecnológicos e do esoterismo do conhecimento em nome do princípio da igualdade do acesso ao discurso, à competência cognitiva e à competência linguística. $\bigcirc$ senso comum é superficial porque desdenha das estruturas que estão para além da consciência, mas, por isso mesmo, é exímio em captar a profundidade horizontal das relações conscientes entre pessoas e entre pessoas e coisas. O senso comum é indisciplinar e imetódico; não resulta de uma prática especificamente orientada o para produzir; reproduz-se espontaneamente no suceder quotidiano da vida. Por último, o senso comum é retórico e metafórico; não ensina, persuade (SANTOS, 2009, p. 89-90).

$\bigcirc$ conceito de senso comum adquire centralidade nessa perspectiva, por possibilitar o desenvolvimento de mudanças substantivas na esfera econômica, política e social. Como menor denominador daquilo que um indivíduo ou grupo acredita, o senso comum possui uma "vocação solidarista e transclassista" (SANTOS, 1989, p. 37), cujas implicações, numa sociedade de classes, marcada pela ciência moderna, não podem

[...] deixar de assumir um viés conservador e preconceituoso, que reconcilia a consciência com as injustiças, naturaliza a desigualdade, e mistifica o desejo de transformação. Porém, opô-lo, por 
essas razões, à ciência como quem opõe as trevas à luz não faz hoje sentido por muitas outras razões. Em primeiro lugar, porque, se é certo que o senso comum é o modo como os grupos ou classes subordinados vivem a sua subordinação, não é menos evidente que, [...] essa vivência, longe de ser meramente acomodatícia, contém sentidos de resistência que, dadas as condições, podem desenvolver-se e transformar-se em armas de luta (SANTOS, 1989, p. 37).

Daí a importância de transformar o conhecimento científico em um novo senso comum, formando uma racionalidade composta de diversas racionalidades. A proposta de uma ciência pós-moderna está pautada na afirmação do elo entre o conhecimento, a ética e a política, a partir do questionamento do papel do conhecimento no enriquecimento ou empobrecimento da vida humana. Mais ainda, o conhecimento é parte de uma racionalidade que visa não somente à compreensão do real, mas também à sua transformação ${ }^{13}$. Em outras palavras, o conhecimento precisa estar comprometido com o viver bem, permitindo a satisfação pessoal desde a sua produção até o seu usufruto.

\section{Considerações finais}

Ao longo deste trabalho, procurou-se mostrar como o conceito de conhecimento comum é amplo e problemático, muitas vezes abarcando o conhecimento popular e o senso comum. Foram utilizados como eixos categoriais o sentido de superioridade da ciência, os conceitos congêneres de interdisciplinaridade, a valoração dos saberes não científicos e a relação entre ciência e política, porque é sobre esses eixos que residem os principais pontos de divergência entre os autores representantes de cada uma das vertentes analisadas. E somente com concessões recíprocas em cada um desses eixos é que seria possível integrá-los, isto é, abrir mão da noção de hierarquia ou de superioridade da ciência, valorizar os saberes populares e promover uma ciência (ou tecnologia) mais comprometida com as transformações sociais.

A partir da discussão das vertentes, tornou-se possível perceber que as relações entre conhecimento comum e conhecimento científico são mais complexas do que se supõe, apontando para o caráter processual dessas formas de saber, que variam conforme o tempo e as circunstâncias de sua produção. A abrangência dos conceitos de conhecimento comum e seus correlatos (saber 
popular, senso comum) denota a importância de um tratamento mais analítico desses conceitos, observando as diferenças entre eles la que saberes se referem, se aqueles tradicionais dos povos e grupos étnicos, por exemplo), e o referencial ou a vertente de sua fundamentação.

A vertente clássica tem o mérito de distinguir os saberes vulgares e científicos, mesmo reconhecendo que esses conhecimentos não estão livres de influências recíprocas; contribui para salvaguardar a especificidade de cada campo do saber, reforçando o caráter profissionalizado da atividade científica (comprometida com a produção de saber e a formulação de teorias) e os valores subjacentes a essa prática (da dúvida, por exemplo, que se expressa no ato de sujeitar o conhecimento a contínuo exame e revisão). Por mais que o sujeito que detém o conhecimento vulgar também possa ser reflexivo e questionador, esse tipo de saber, pela sua própria processualidade, não se caracteriza pelo comprometimento, além de apresentar-se carente de sistematização e método.

Outro mérito dessa vertente é o fato de reconhecer a importância do saber vulgar sem deixar de alertar para os seus perigos. É o caso da pseudociência ou corpo de saberes que se faz passar por científico, muitas vezes, de modo desonesto. Além disso, seu sistematizador lança um alerta para a redu92 ção da realidade concreta à dimensão empírica, privilegiada nessa forma de saber. Já do ponto de vista da valorização do saber, o conhecimento comum é, por vezes, considerado até mais rico no tocante ao conteúdo de seu saber do que o próprio conhecimento científico no que diz respeito ao conhecimento de pessoas ou de situações particulares.

A vertente clássica também apresenta a vantagem de reconhecer que a formação de uma atitude científica pode ser muito mais frutífera do que intervenções diretas na realidade, uma vez que a formação dessa atitude contribuiria, ainda que indiretamente, com o exercício da cidadania Imaior cautela com posições políticas próprias e alheias, bem como o respeito e a tolerância de posições ideológicas contrárias, exercício de pensamento crítico, cuidadoso e sempre atento aos seus próprios erros nas esferas de participação social). Trata-se aqui de cultivar o conhecimento como valor central.

$\bigcirc$ principal problema dessa vertente estaria no seu excesso de confiança na superioridade da ciência, ainda que seu proponente não afirme essa superioridade de modo absoluto, reconhecendo-a somente em termos metodológicos. É questionável se essa confiança não conduza ao desprezo do saber 
vulgar, considerado inferior sob o referido ponto de vista, enquanto o mais adequado, numa postura científica, seria examiná-lo e questioná-lo continuamente.

defensor da vertente marxista gramsciana, dada a proximidade de alguns posicionamentos com o teórico da perspectiva clássica, compartilha com alguns méritos e dificuldades dessa tendência. Um diferencial da perspectiva marxista gramsciana é o de que, por meio dela, se explicita a necessidade de promover o acesso dos componentes das classes populares aos processos e produtos do conhecimento científico e tecnológico como estratégia para combater a desigualdade. Trata-se do entendimento de que a ciência e a tecnologia tornaram-se elementos valiosos na disputa pela hegemonia, sendo apropriados pelas classes dominantes. A preocupação central seria a de promover o acesso e o protagonismo dos subalternos no que diz respeito aos processos e produtos do conhecimento científico-tecnológico.

Uma das dificuldades na defesa dessa vertente está em atribuir um caráter eminentemente negativo ao conhecimento popular, parecendo aproximá-lo do conceito de alienação. Embora Jantsch (1995) reconheça a importância do conhecimento popular para o debate científico (novas perguntas e ideias a serem examinadas), percebe poucos elementos positivos nesse saber, que, supostamente, contribuiria para a formação de um modo subalterno de pensar. Com seu excesso de confiança no conhecimento científico, perde de vista que um processo de democratização do saber implica igualmente o respeito pelos saberes populares e o seu reconhecimento.

É, aliás, o estabelecimento de uma hierarquização entre um saber superior e outro inferior que contribui para que o diálogo não ocorra. Também parece utópica a possibilidade de superar ou prescindir do conhecimento comum, sendo antes de qualquer tradição que o oriente, aquele conhecimento básico do dia a dia e que permite, por intermédio da experiência, incrementar o diálogo entre os portadores de diferentes saberes. Parece mais utópico ainda pressupor que somente o conhecimento científico possa conduzir a uma práxis revolucionária e transformadora.

Por último, o defensor da vertente transformadora tem o mérito de não estabelecer relações hierárquicas entre os saberes, enfatizando tanto os pontos positivos do senso comum quanto aqueles do conhecimento científico, embora atribua maior importância às tecnologias do que propriamente à ciência (concepção pragmática do conhecimento). Isto porque a ciência é compreendida 
como um conhecimento que não se reverteu em benefícios para a vida de todos os seres humanos.

Para o proponente da perspectiva transformadora, abordar o conhecimento do ponto de vista da sua superioridade/inferioridade somente contribui para reforçar as desigualdades entre esses conhecimentos. Conforme Boaventura de Sousa Santos, para alcançar a justiça e a democracia entre os saberes, é preciso desenvolver ações que reconheçam, respeitem e tolerem os saberes populares e, sobretudo, que promovam o diálogo e o intercâmbio com vistas à construção de novas racionalidades. Assim, depreende-se que a perspectiva transformadora inclina-se mais para a horizontalidade entre essas formas de saber, embora, em última instância, defenda um nível de senso comum mais elaborado e aprimorado com o auxílio do conhecimento científico.

$\bigcirc$ diferencial da perspectiva transformadora é que, por meio dela, se percebe, no conhecimento comum, o seu potencial para conduzir (ou inibir) mudanças nas esferas política, econômica, social e cultural. Por isso é um conhecimento que não pode ser ignorado. É possivel aventar que a relação desse conhecimento com a ciência é diferente da relação com a tecnologia, de cuja mediação espera-se a solução de problemas práticos. $\bigcirc$ educador, comumente, é desafiado a dialogar com esses saberes ou até mesmo integrá-los, de modo a estabelecer acordos provisórios e promover as mudanças necessárias. Não é tarefa fácil, pois é preciso proceder sem desrespeitar o saber popular e sem impor o saber técnico.

Já a ciência não pode integrar-se simplesmente ao conhecimento comum - tarefa impossível ou mesmo utópica ${ }^{14}$ - sob o risco de descaracterizar-se. É possível que possuidores desses diferentes conhecimentos dialoguem e troquem saberes la exemplo das pesquisas científicas iniciadas a partir do saber popular que acredita na influência da Lua no desenvolvimento da agricultura ${ }^{15}$ ), mas não ao ponto de se confundirem numa totalidade heterogênea e eclética. Isso não exclui que o cidadão não possa, a partir do diálogo e da integração dos pontos em comum desses saberes, encontrar um bom senso ou aquilo que seria a sabedoria para a vida proposta no corpus da perspectiva transformadora.

Assim, o ponto problemático da perspectiva transformadora é a diluição das peculiaridades de cada saber, resultando num relativismo. Se são 
os juízos de valor que determinam a preferência pela ciência, como explica Santos (1989), não são quaisquer valores que fazem dela uma atividade diferente de outras. São valores específicos como a racionalidade (coerência), a verdade e o respeito aos fatos, segundo Cupani (2006), os ideais que conformam a peculiaridade da atitude científica, isto é, aquilo que o bom cientista persegue no seu fazer cotidiano.

Cupani (2006) distingue a atitude científica da pesquisa científica. Esta última nem sempre está à altura do ideal esboçado pela atitude científica, podendo ser mais ou menos correta, eficiente, útil ou honesta. Mas antes que qualquer falha na pesquisa científica conduza ao relativismo, os ideais ou a confiança nos valores da atitude científica pressupõem que se busque um conhecimento cada vez mais rico, seguro e correto.

Outra maneira de pensar a democratização do saber é a partir do reconhecimento das suas diferenças e do estabelecimento de um diálogo e de uma integração dentro do possível. Talvez assim o conhecimento comum, como um saber distinto, continuaria auxiliando a ciência a construir objetos a partir de sua aparente simplicidade de ideias, ao passo que o conhecimento científico poderia repensar, teoricamente, os conteúdos do conhecimento comum.

Assim, em vez de uma hierarquização entre os saberes, parece mais adequado considerar as particularidades e as diferenças existentes entre eles em vista da multi/interdisciplinaridade.

\section{Notas}

1 A autora agradece a Profa. Dra. Maria Del Carmen Cortizo, pelos questionamentos que motivaram o desenvolvimento deste trabalho na ocasião da disciplina de Atividade Supervisionada, ministrada no primeiro semestre de 2013, no curso de Pós-graduação em Serviço Social da Universidade Federal de Santa Catarina.

$2 \bigcirc$ conhecimento comum pode configurar-se a partir de grandes visões sintéticas (generalização) ou de pensamentos fragmentários.

3 Por exemplo, o conhecimento comum formula enunciados (opiniões), assim como o saber científico, embora esse último os fundamente e elabore conjeturas possíveis de verificar e testar.

4 Embora uma pseudociência possa transformar-se em uma ciência, caso aprimore seus procedimentos.

5 Gramsci foi um autor que buscou os traços que caracterizavam o conhecimento popular, uma vez que tinha em vista a organização de uma possível contra-hegemonia das classes subalternas. 
Três perspectivas de análise dos saberes: multidisciplinaridade e interdisciplinaridade

6 No entendimento de Jantsch (1995), o conhecimento popular não se confunde meramente com o senso comum e, embora se relacione com ele, diz respeito ao conhecimento que está atrelado à cultura, às tradições dos diversos grupos humanos, ao folclore, à religião etc.

7 Apesar de muito diferentes em sua motivação e em seus propósitos, esta visão pode ser comparada à do filósofo Gaston Bachelard (1972), para quem a ciência só pode ser negação do conhecimento vulgar, cujas crenças e convicções constituem-se mais em obstáculos epistemológicos do que em pontos de partida efetivos para a construção do conhecimento científico.

8 Os exemplos das características a seguir também são extraídos dos obras dos autores.

9 Outro exemplo de imediaticidade e de acriticidade que pode ser agregado ao exemplo dos autores é quando um sujeito julga adequado o consumo da água de um rio ou de uma fonte pelo seu aspecto límpido ou cristalino, conformando-se com a aparência e com os conhecimentos sensoriais, ao passo que na ciência a água é submetida a uma análise para identificar a sua potabilidade.

10 Vale destacar ainda que ele se apresenta como resto ou resíduo de conhecimentos científicos ultrapassados.

11 Para favorecer o acesso dos componentes das classes populares ao conhecimento científico, é necessário captar o estágio lógico-processual do grupo em questão, as características do seu senso comum e o conteúdo que os sustenta.

12 Na interpretação do autor, o conceito filosófico do senso comum, por exemplo, surgiu no século $\mathrm{XVIII}$, ligado ao combate ideológico da burguesia contra o irracionalismo do mundo feudal. Quando a burguesia conquistou o poder, o senso comum perdeu as características da razão e da prudência que mantinha até então, tornando-se superficial e ilusório (SANTOS, 1989).

13 As ideias de autonomia da ciência clássica e de desinteresse do conhecimento científico não se sustentam, para Santos (2009), que aponta o fenômeno global da industrialização das ciências, nas décadas de 1930 e 1940, como exemplos de direcionamento político da ciência, tanto na organização da investigação quanto na aplicação dos seus resultados. $\bigcirc$ fenômeno ocorreu nas sociedades capitalistas e socialistas do leste europeu.

14 Ainda que a utopia seja válida como horizonte para guiar as ações humanas. Sobre a utopia vale consultar a obra organizada por Bianchetti e Thiesen (2014) intitulada "Utopias e Distopias na Modernidade".

15 Vide revisão de literatura realizada por Jovchelevich (2006).

\section{Referências}

BACHELARD, Gaston. Conhecimento comum e conhecimento científico. Tempo Brasileiro, São Paulo, n. 28, p. 47-56, jan./mar. 1972.

BIANCHETTI, Lucídio; THIESEN, Juares da Silva (Org.). Utopias e distopias na Modernidade: educadores em diálogo com T. Morus, F. Bacon, J. Bentham, A. Huxley e G. Orwell. ljuí: Editora Unijuí, 2014. 
BUNGE, Mario. La investigación científica: su estrategia y su filosofia. 7. ed. Barcelona: Ariel, 1980.

Treatise on basic philosophy. Dordrecht: Reidel, 1985. (v. 6).

CHAUÍ, Marilena. Convite à filosofia. 13. ed. São Paulo: Ática, 2008.

CUPANI, Alberto Oscar. Sobre a importância de certos valores na ciência. In: STEIN, Sofia; KUIAVA, Evaldo (Org.). Linguagem, ciência e valores: sobre as representações humanas no mundo.Caxias do Sul: Educs, 2006.

JANTSCH, Ari Paulo. O conhecimento popular e a hegemonia. In: SCHAEFER, Sérgio; JANTSCH, Ari Paulo (Org.). O conhecimento popular. Petrópolis, RJ: Vozes, 1995.

; BIANCHETTI, Lucídio. Interdisciplinaridade e Universidade. In: JANTSCH, Ari Paulo; BIANCHETTI, Lucídio (Org.). Interdisciplinaridade: para além da filosofia do sujeito. 9. ed. Petrópolis, RJ: Vozes, 2011.

JOVCHELEVICH, Pedro. Revisão de literatura sobre a influência dos ritmos astronômicos na agricultura. Revista Núcleo de Pesquisa Interdisciplinar. São Paulo, 2006. Disponível em: http://www.fmr.edu.br/npi_2.php. Acesso em: 26 jun. 2014.

LYOTARD, Jean-François. A condição pós-moderna. 8. ed. Rio de Janeiro: José Olympio, 2004.

MARCONI, Marina de Andrade; LAKATOS, Eva Maria. Fundamentos da metodologia científica. 7. ed. São Paulo: Atlas, 2010.

PAVIANI, Jayme. Epistemologia prática: ensino e conhecimento científico. Caxias do Sul: Educs, 2009.

SANTOS, Boaventura de Sousa Santos. Introdução a uma ciência pós-moderna. Rio de Janeiro: Graal, 1989.

2007 .

Renovar a teoria crítica e reinventar a emancipação social. São Paulo: Boitempo,

Um discurso sobre as ciências. São Paulo: Cortez, 2009.

SCHAEFER, Sérgio; JANTSCH, Ari Paulo. O conhecimento popular. Petrópolis: Vozes, 1995.

VATTIMO, Gianni. O fim da modernidade: niilismo e hermenêutica na cultura pós-moderna.

2. ed. São Paulo: Martins Fontes, 2007. 
; ROVATTI, Pier Aldo (Ed.). El pensamiento débil. Madrid: Cátedra, 1988.

Ms. Fernanda Nunes da Rosa Mangini

Universidade Federal de Santa Catarina

Bolsista do Programa de Doutorado Sanduíche no Exterior | PDSE Bolsista da Coordenação de Aperfeiçoamento de Pessoal de Nível Superior | CAPES

E-mail | fernandapesquisadora@gmail.com

Prof. Dr. Lucídio Bianchetti

Universidade Federal de Santa Catarina Departamento de Estudos Especializados em Educação Programa de Pós-Graduação em Educação Pesquisador 1B | CNPq E-mail | lucidio.bianchetti@pq.cnpq.br

Recebido 4 set. 2014 Aceito 17 nov. 2014 